\title{
Entrelacs
}

Cinéma et audiovisuel

HS | 2012

Le post-humain et les enjeux du sujet

\section{Une mutation anthropologique}

\section{Marie-Jean Sauret}

\section{OpenEdition}

Journals

Édition électronique

URL : http://journals.openedition.org/entrelacs/288

DOI : 10.4000/entrelacs.288

ISSN : 2261-5482

Éditeur

Éditions Téraèdre

Édition imprimée

Date de publication : 2 février 2012

ISBN : 978-2296567177

ISSN : 1266-7188

Référence électronique

Marie-Jean Sauret, « Une mutation anthropologique », Entrelacs [En ligne], HS | 2012, mis en ligne le 01 août 2012, consulté le 19 avril 2019. URL : http://journals.openedition.org/entrelacs/288 ; DOI :

10.4000 /entrelacs.288

Ce document a été généré automatiquement le 19 avril 2019.

Tous droits réservés 


\title{
Une mutation anthropologique
}

\author{
Marie-Jean Sauret
}

1 Le texte complet de cet article est publié dans l'ouvrage :

Post humain et les enjeux du sujet

Editeur : L'HARMATTAN (2 février 2012)

Collection Ouverture Philosophique

ISBN-10 : 2296567177

ISBN-13 : 978-2296567177

\section{RÉSUMÉS}

Le sujet peut-il habiter n'importe quelle modalité du social et à quelle condition ? Chaque époque secrète l'anthropologie avec laquelle il est amené à se penser et parfois à confondre cette suggestion avec des invariants définitifs. Pour autant, il y a à apprendre des anthropologies inventées par les humains jusque là pour examiner les problèmes à résoudre (dans la relation du sujet au « vivre ensemble ») et les solutions disponibles ou à inventer...

\section{AUTEUR}

\section{MARIE-JEAN SAURET}

Professeur de psychopathologie clinique à l'Université Toulouse Le Mirail, directeur de recherches au Laboratoire de Psychopathologie clinique et psychanalyse de l'université de Provence 